\title{
Установка для измерения АЧХ СВЧ-фотодиодов
}

\author{
Ю. Синельников ${ }^{1}$
}

УДК 621.383.52 | ВАК 05.11.01

\begin{abstract}
Мытищинский научно-исследовательский институт радиоизмерительных приборов (МНИИРИП) - головная научно-исследовательская испытательная организация Минпромторга России в сфере развития и применения электронной компонентной базы - осуществляет научно-методическую координацию работ по созданию и проведению испытаний ЭКБ различного назначения. Перспективное направление - радиофотонные системы связи, которые отличаются рядом преимуществ по сравнению с традиционными радиоэлектронными системами, применяемыми в радиолокации. Для определения характеристик СВЧ-фотодиодов во ФГУП "МНИИРИП" была собрана и опробована измерительная установка, позволяющая измерять АЧХ фотодиодов в диапазоне до сотен гигагерц.
\end{abstract}

\section{ВВЕДЕНИЕ}

Современные системы сбора, обработки и передачи информации работают со все более возрастающими объемами данных. Чтобы обеспечить точность и скрытность функционирования систем специального назначения, необходимо распределять в пространстве их составные части, которые нуждаются в высокоскоростном обмене информацией между собой, в неискаженном виде и на любом требуемом расстоянии. Размещение этих систем на мобильных объектах накладывает дополнительные ограничения по объему и массе.

Один из способов соблюдения предъявляемых требований-применение устройств радиофотоники, которые объединяют в себе компоненты СВЧ-радиоэлектроники, интегральной и волновой оптики, оптоэлектроники и изделий из ряда других областей. Радиофотонные устройства кардинально превосходят электронные устройства в силу физических свойств фотонов - в отличие от электронов они не имеют массы, заряда и не создают сопротивления при перемещении.

Этими факторами обусловлены следующие свойства устройств на базе радиофотоники:

- радиофотонные генераторы сигналов отличаются низким уровнем фазового шума, который мало зависит от частоты генерации, высокой устойчивостью к электромагнитным помехам, вибрации и ускорению;

- спомощью радиофотонных генераторов можно формировать импульсы длительностью менее $10^{-10} \ldots 10^{-15}$ секунды, что значительно меньше длительности

ФГуп «Мниирип», инженер-испытатель 1 категории. самых коротких импульсов, формируемых традиционными электронными генераторами;

- радиофотонные системы позволяют с малыми потерями передавать аналоговые СвЧ-сигналы без обработки в неискаженном виде по волоконнооптическим линиям на любые расстояния.

Радиофотонные компоненты перспективны для использования в радиолокационных системах с фазированными антенными решетками, распределенных системах радиосвязи и радиоэлектронной борьбы, а также в измерительной СВЧ-технике [1].

\section{СХЕМА УСТАНОВКИ И РЕЗУЛЬТАТЫ ИЗМЕРЕНИЙ}

Для полной реализации преимуществ применения устройств на основе радиофотоники требуются, в частности, мощные СВЧ-фотодиоды, работающие в спектральном диапазоне 1250-1650 нм с шириной диапазона частот до десятков и сотен гигагерц [2]. Отечественная промышленность осваивает производство этих изделий в рамках программ по импортозамещению на фоне все более усиливающихся технологических санкций.

Один из основных параметров СвЧ-фотодиодов - амплитудно-частотная характеристика.

Для оценки частотныххарактеристик фотодиодов можно использовать следующие измерительные комплексы и отдельные устройства:

- анализатор оптических компонентов Keysight N4373D (комплексное решение);

- оптоэлектронный калибровочный модуль Anritsu MN4765B (дополнительно требуются лазерный источник излучения, оптический модулятор и векторный анализатор цепей Anritsu серии MS4640B); 


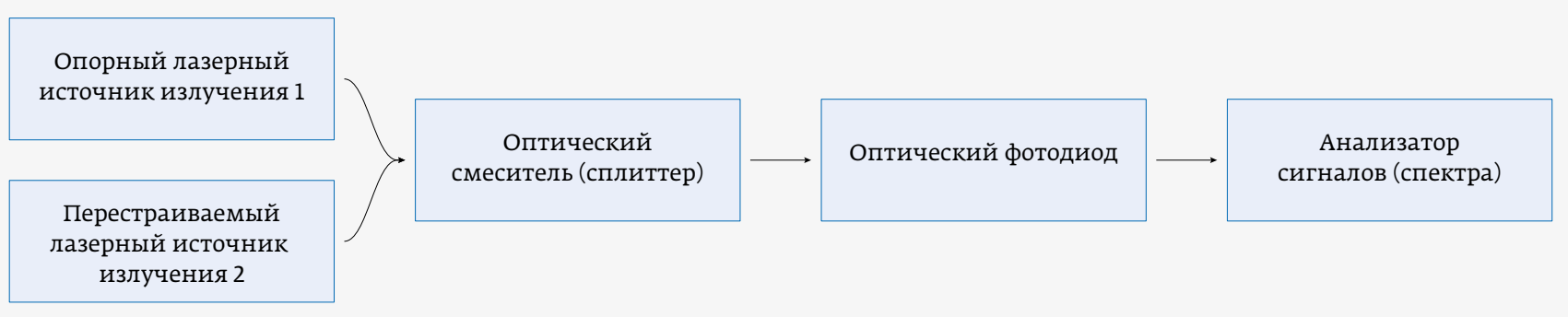

Рис. 1. Укрупненная структурная схема установки для измерения АЧХ фотодиодов

- электрооптический конвертор Thorlabs MX40G (дополнительно требуются векторный анализатор цепей и файл параметров для калибровки S2P).

Для всех этих приборов характерны ограничения по СВЧ-диапазону частот, накладываемые применяемыми оптическими модуляторами.

Для оценки возможности и решения задачи измерения АЧХ СВЧ-фотодиодов в испытательном центре ФГУП «МНИИРИП» при содействии представительства фирмы Keysight в Москве и АО "Центр ВОСПИ» была собрана измерительная установка, укрупненная структурная схема которой представлена на рис. 1.

Принцип работы установки основан на сложении двух гармонических колебаний $a_{1}$ и $a_{2}$ с близкими частотами $\omega_{1} и \omega_{2}$.

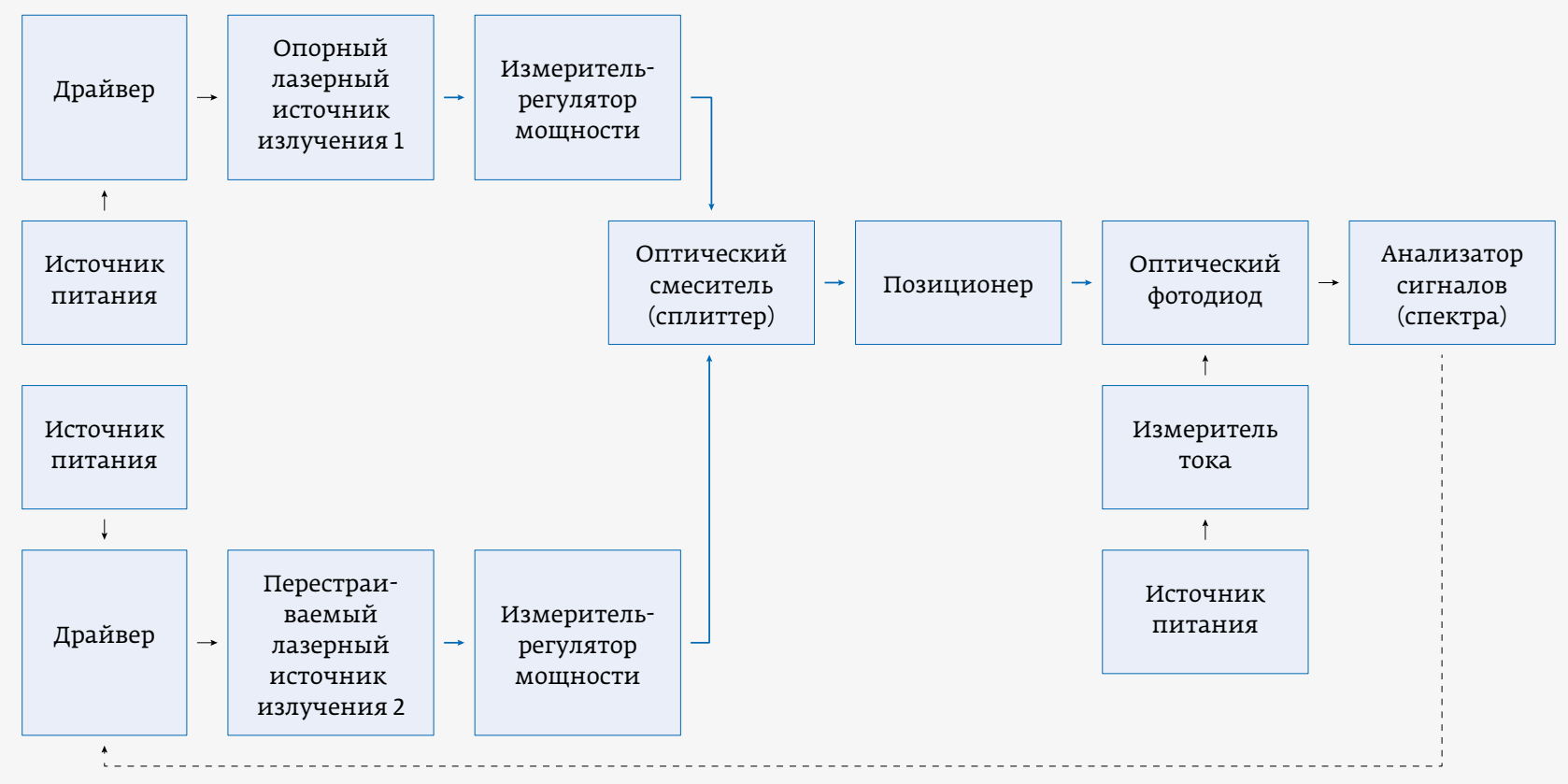

Уравнение суммы этих колебаний можно представить в виде:

$$
a=a_{1}+a_{2}=A_{1} \sin \left(\omega_{1} t+\varphi_{1}\right)+A_{2} \sin \left(\omega_{2} t+\varphi_{2}\right) .
$$

При равенстве амплитуд $A_{1}=A_{2}=A$ и выборе точки отсчета начальных фаз $\varphi_{1}=\varphi_{2}=0$ уравнение (1) принимает вид:

$$
a=A\left(\sin \left(\omega_{1} t\right)+\sin \left(\omega_{2} t\right)\right)
$$

Исключив время и преобразовав уравнение (2), получим:

$$
a=2 A\left(\sin \frac{\omega_{1}+\omega_{2}}{2} \cos \frac{\omega_{1}-\omega_{2}}{2}\right) .
$$




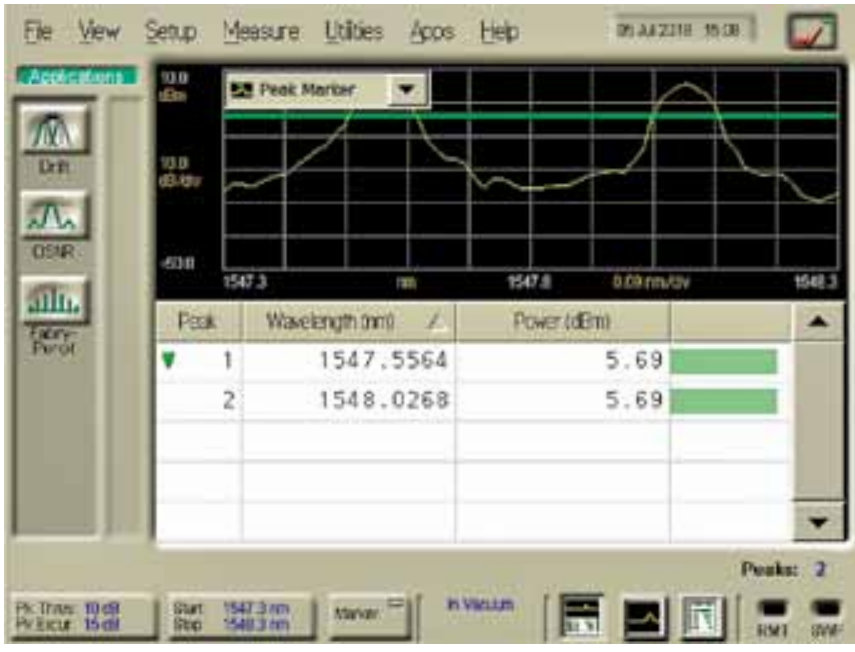

Рис. 3. Результаты измерения сигнала на выходе сплиттера

Из выражения (3) следует, что результирующее колебание будет иметь две составляющие:

- первая - со средней частотой сигнала $\omega_{0}$ между $\omega_{1} и \omega_{2}$

$$
\omega_{0}=\frac{\omega_{1}+\omega_{2}}{2}
$$

- вторая - с частотой модуляции $\omega_{m}$ сигнала $\omega_{0}$ :

$$
\omega_{\mathrm{m}}=\frac{\omega_{1}-\omega_{2}}{2} \text { или, если } \Delta \omega=\omega_{1}-\omega_{2} \text {, то } \omega_{m}=\frac{\Delta \omega}{2} .
$$

То есть, подавая на вход смесителя (см. рис. 1) двух сигналов от двух лазерных источников (с частотой $f_{1}$ и частотой $f_{2}$, соответственно) и облучая суммарным сигналом фотодиод, на его выходе мы получим сигнал с частотой $f_{m}$, равной половине разности частот $\Delta f=\left|f_{1}-f_{2}\right|$ :

$$
f_{m}=\frac{\Delta f}{2} \text {. }
$$

Детальная структурная схема установки представлена на рис. 2.

В качестве источников излучения в установке используются одномодовые лазерные источники фирмы Keysight диапазона 1550 нм:

- источник излучения 1 - эталонный лазерный передатчик 81490А;

- источник излучения 2 - перестраиваемый лазерныЙ ИСтОчнИк N77І1А.

Данные устройства включают в себя источники питания и драйверы согласно схеме, приведенной на рис. 2.

Измерители-регуляторы мощности позволяют выровнять амплитуды сигналов лазерных источников для достижения 100\%-ной глубины модуляции. В данной установке используются 2-канальный аттенюатор

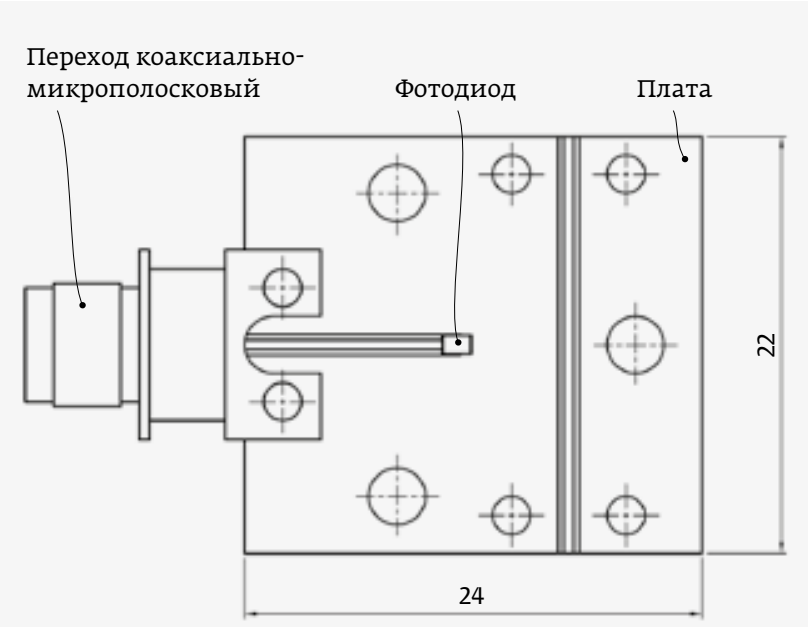

Рис. 4. Чертеж измерительной платы фотодиода

и измеритель мощности оптического излучения Keysight N7762A.

В качестве оптического смесителя применяется изготовленный в АО «Центр ВОСПИ» сплиттер, для которого характерно равное затухание в каждом плече. Контроль мощности на выходе устройства выполнялся до сборки установки с помощью многоволнового измерителя длины волны Keysight 86120D. Результаты измерений сигнала на выходе сплиттера представлены на рис. 3.

Суммарный сигнал после сплиттера по оптическому волокну через позиционер подается на испытуемый фотодиод, который облучается через открытый скол оптического волокна. В качестве устройств совмещения оптических осей волокна и фотодиода используются позиционеры сигнальных зондов станции Signatone WL-250A. Фотодиод смонтирован на измерительной плате методом flipchip. Чертеж измерительной платы приведен на рис. 4.

Для крепления оконечной части волокна и фотодиода с измерительной платой на позиционерах были изготовлены оснастки. Внешний вид оснасток и фотодиода на измерительной плате представлен на рис. 5.

Питание на фотодиод подается через измерительный разъем с помощью устройств смещения Bias Keysight 11612B. В качестве измерителя тока используется
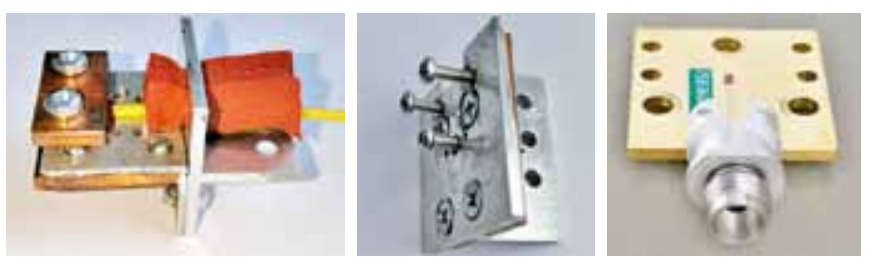

Рис. 5. Внешний вид оснасток и фотодиода на измерительной плате 


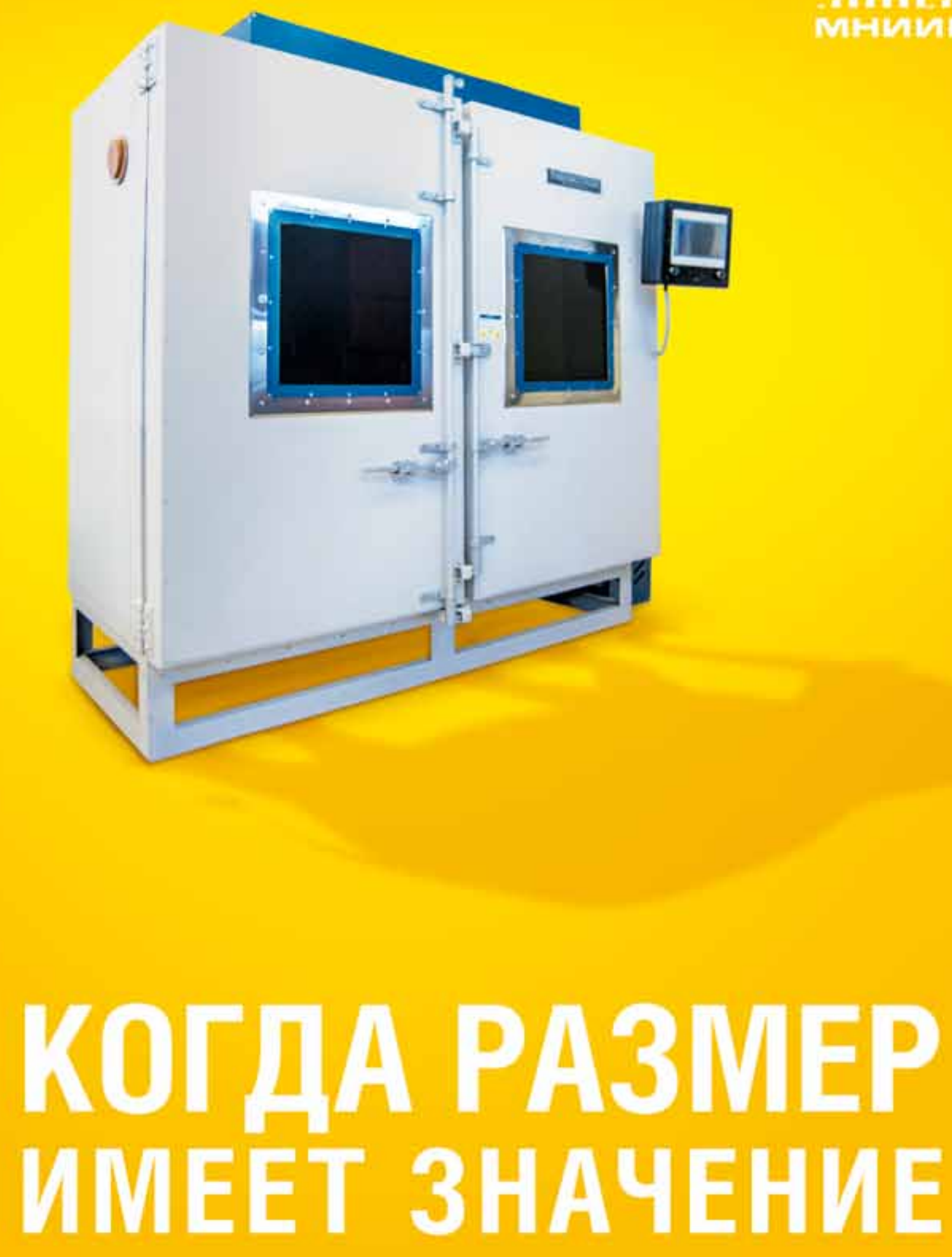

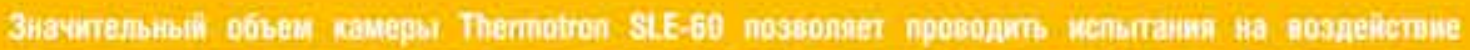

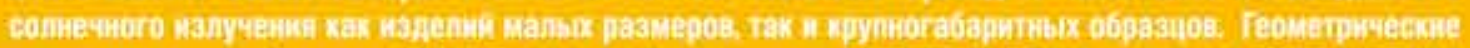

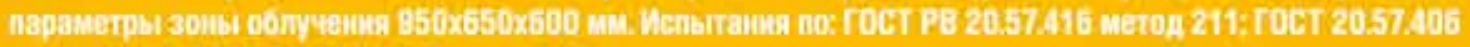

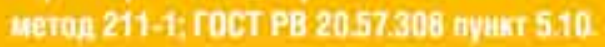



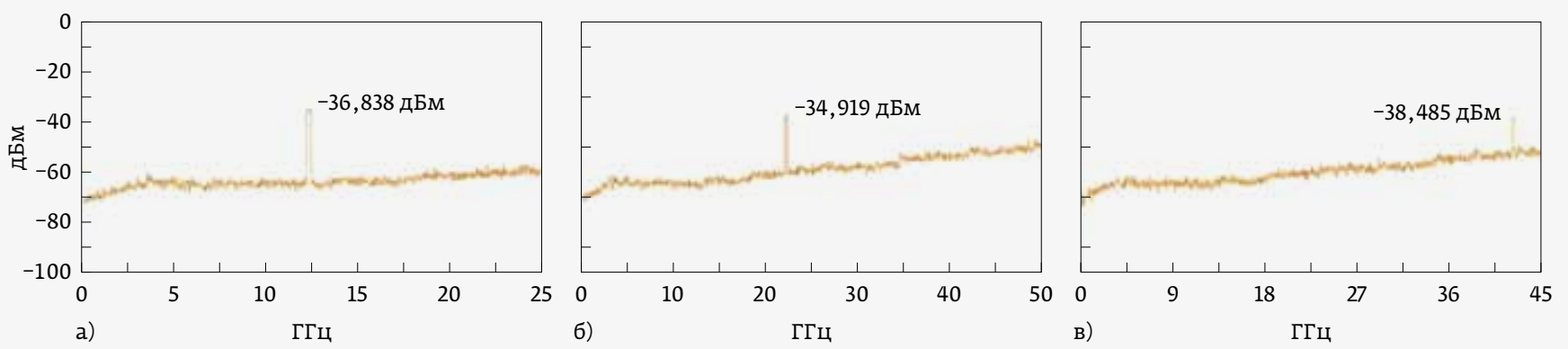

Рис. 6. Уровни сигналов при разных частотах модуляции: а) 12,330 ГГц; б) 22,260 ГГц; в) 42,10 ГГц

миллиамперметр, по максимальным показаниям которого происходит совмещение оптических осей облучающего волокна и фотодиода путем перемещения их позиционерами. С измерительным прибором - анализатором сигналов Keysight N9030A - выход фотодиода соединен коаксиальным кабелем через разъем 2,4 мм.

Пунктирной стрелкой на схеме (см. рис. 2) показана возможная связь измерительного прибора с драйвером перестраиваемого источника лазерного излучения для реализации его автоматической перестройки по частоте.

На рис. 6 представлены полученные на измерительной установке уровни сигналов при разных частотах модуляции.

\section{ЗАКЛЮЧЕНИЕ}

Разработанная и испытанная во ФГУП «МНИИРИП» установка позволяет проводить измерения АЧХ фотодиодов в более широком диапазоне частот, который обычно ограничен возможностями модулятора Маха-Цандера, используемого в современных измерительных приборах.
Применяемые в установке физические явления обеспечивают высокую линейность оптико-электронных преобразований, что позволяет повысить точность измерений.

Кроме того, суммарная стоимость компонентов установки значительно ниже стоимости анализаторов оптических компонентов, что обеспечивает снижение затрат на измерения.

\section{ЛИТЕРАТУРА}

1. Малышев С. А., Чиж А. Л., Микитчук К. Б. Волоконнооптические лазерные и фотодиодные модули СВЧ-диапазона и системы радиофотоники на их основе // Материалы 4-й Всероссийской конференции «Электроника и микроэлектроника СВч», Санкт-Петербург, Россия, 2015.

2. Чиж А.Л., Малышев С. А., Микитчук К.Б., Журавлев К.С. и др. Мощный СВЧ-фотодиод Шоттки на основе двойной гетероструктуры InAIAs / InGaAs // «Электроника и микроэлектроника СВЧ», издательство СанктПетербургского государственного электротехнического университета «ЛЭТИ» им. В.И. Ульянова (Ленина), СанктПетербург, Россия, 2018.

\section{КНИГИ ИЗДАТЕЛЬСТВА "ТЕХНОСФЕРА"}

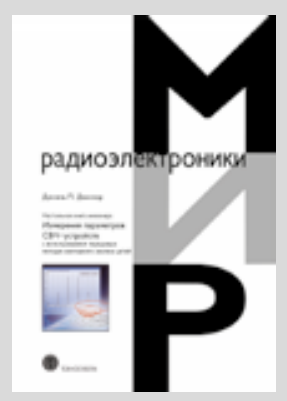

Цена 1600 руб.
НАСТОЛЬНАЯ КНИГА ИНЖЕНЕРА

ИЗМЕРЕНИЯ ПАРАМЕТРОВ СВЧ-УСТРОЙСТВ С ИСПОЛЬЗОВАНИЕМ ПЕРЕДОВЫХ МЕТОДИК ВЕКТОРНОГО АНАЛИЗА ЦЕПЕЙ Дансмор Джоэль П.

Издание осуществлено при поддержке Keysight Technologies

В книге рассмотрен широкий круг измерительных задач в СВЧ-диапазоне. В центре внимания - измерения активных и пассивных устройств с использованием новейших методик векторного анализа цепей, методики их калибровки, подходы к анализу полученных результатов. Приведены практические примеры измерений параметров таких устройств, как кабели и соединители, линии передачи, фильтры, направленные ответвители и др.

Книга станет прекрасным практическим руководством для инженеров-метрологов и разработчиков ВЧ-/ СВЧ-устройств.

КАК ЗАКАЗАТЬ НАШИ КНИГИ?

$凶$ 125319, Москва, а/я 91; + +7 495 234-0110; \$ +7 495 956-3346; knigi@technosphera.ru, sales@technosphera.ru 


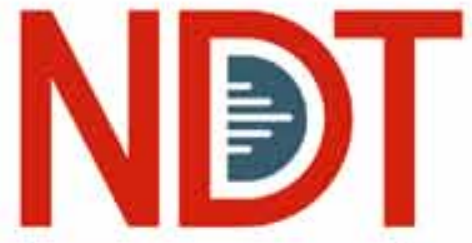

RUSSIA

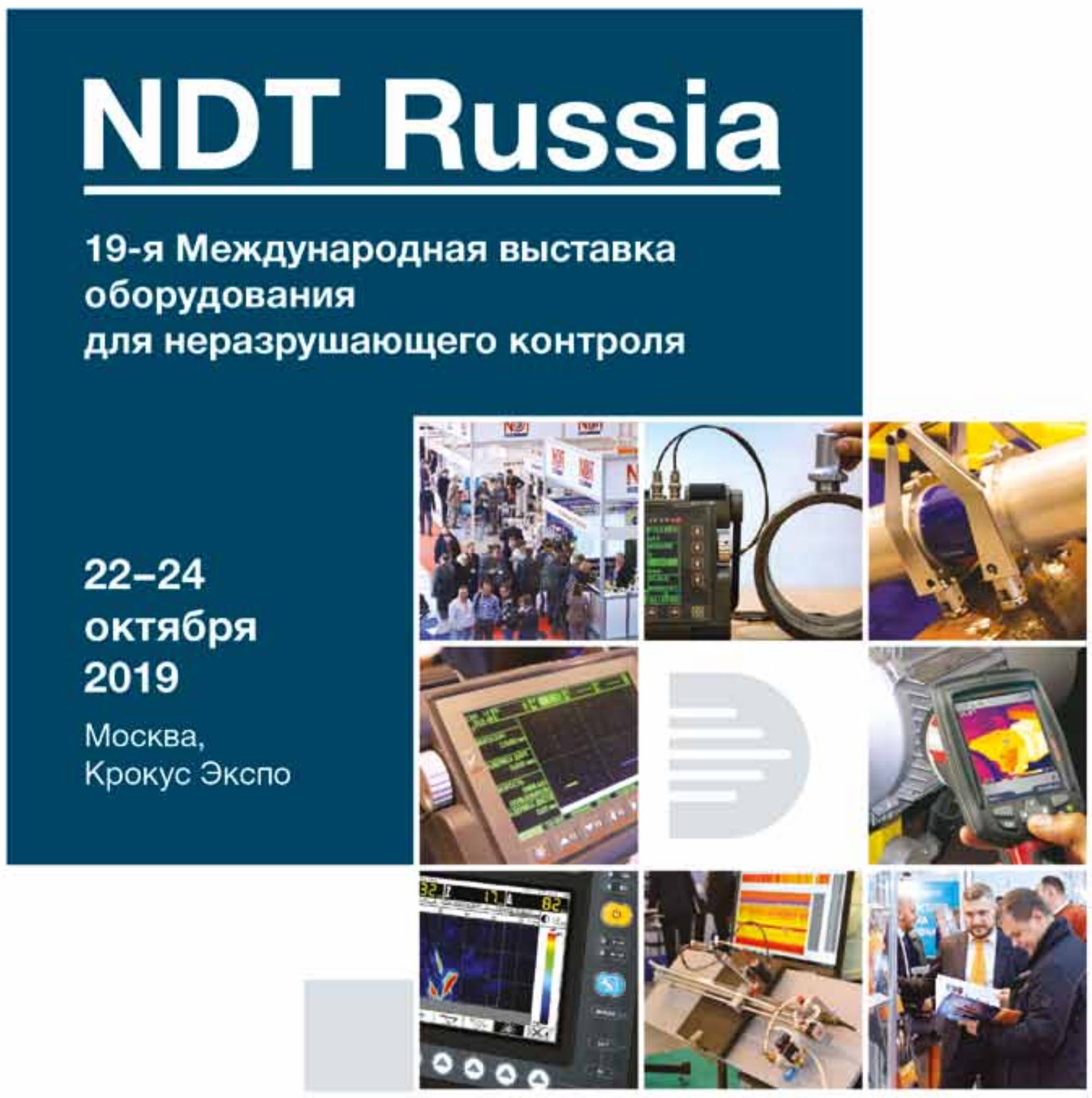

Opranизатор - хомпания MVK Oфuc B Cankt-Петербурre

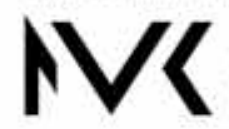

$+7(812) 3806010 / 00$ ndt amvk.ru
Получите бесплатный

электронный билет на сайте

ndt-russia.ru,

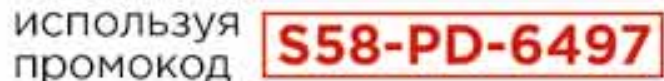

